\title{
Short-term climatic impacts of afforestation in the East Asian monsoon region
}

\author{
MA Di ${ }^{1,2,3^{*}}$, LIU Zheng Yu ${ }^{4,3}$, LÜ ShiHua $^{1}$, MICHAEL Notaro ${ }^{3}$, RONG XinYao ${ }^{5}$, \\ CHENG GuangShan ${ }^{3} \&$ WANG FuYao ${ }^{3}$ \\ ${ }^{1}$ Key Laboratory of Land Surface Process and Climate Change in Cold and Arid Regions, Cold and Arid Regions Environmental and Engineering \\ Research Institute, Chinese Academy of Sciences, Lanzhou 730000, China; \\ ${ }^{2}$ Graduate School of Chinese Academy of Sciences, Beijing 100049, China; \\ ${ }^{3}$ University of Wisconsin, Madison, WI 53706, USA; \\ ${ }^{4}$ Laboratory Climate, Ocean and Atmosphere Studies, Perking University, Beijing 100871, China, \\ ${ }^{5}$ Chinese Academy of Meteorological Sciences, Beijing 100081, China
}

Received September 3, 2012; accepted December 5, 2012; published online February 6, 2013

The influence of changes in vegetation cover on short-term climate over the East Asian monsoon region is simulated using the Community Climate System Model Version 3.5. The results show the annual mean surface air temperature significantly decreases by $0.93^{\circ} \mathrm{C}$ in response to afforestation over the East Asian monsoon region. Also, surface air temperature decreases by 1.46 and $0.40^{\circ} \mathrm{C}$ in summer and winter, respectively. The cooling is caused by enhanced evapotranspiration (ET) produced by increased forest cover. Evapotranspiration is greater in summer than in winter, so summer cooling is greater than winter cooling. The annual mean precipitation increases in response to afforestation, with a maximum of $7 \%$ in April. Water vapor increases significantly because of greater latent heat flux release. Meanwhile, afforestation leads to higher surface roughness, which decreases surface wind speed and induces an ascending air motion. These factors can produce more clouds and precipitation. Moreover, the surface albedo and the reflective solar radiation are reduced in response to afforestation.

East Asian monsoon region, energy budget, forest cover, hydrological cycle, vegetation cover change

Citation: Ma D, Liu Z Y, Lü S H, et al. Short-term climatic impacts of afforestation in the East Asian monsoon region. Chin Sci Bull, 2013, 58: 2073-2081, doi: $10.1007 / \mathrm{s} 11434-012-5661-6$

Vegetation cover change is one of the causes of climate change and may either enhance or mitigate climate change. In recent years, more and more scientists are focusing on the impacts of changes in vegetation cover on global and regional climate [1-6]. Vegetation affects climate mostly through albedo, evapotranspiration and surface roughness [7-10]. Charney [7] speculated overgrazing in the Sahel of Africa could lead to a loss of vegetation, which raises the surface albedo and cools the ground, so subsidence airflow continues and droughts increase in intensity. Notaro et al. [8] found a reduction of boreal forest cover raises surface albedo, decreases surface temperatures through reducing the ab-

*Corresponding author (email: madi@1zb.ac.cn) sorbed radiation energy and extends the period of seasonal snow cover. Also, a reduction in evapotranspiration leads to decreased precipitation and a slowing of the hydrological cycle. Cheng et al. [9] found an increase in the density of forest cover increase the surface roughness and induces convergence, so the anomalous ascent increases cloud cover and precipitation. Also, the ways in which vegetation affects climate may vary by latitudes [10-12]. In high-latitudes, vegetation impacts climate by modifying surface albedo. For example, Thomas and Rowntree [10] found a reduction in the extent of boreal forest leads to an increase in surface albedo and cooling at the surface through decrease solar radiation energy. At low-latitudes, evapotranspiration is the dominant mechanism producing this feedback from vegeta- 
tion. With an atmospheric general circulation model simulation, Dickinson and Kennedy [11] found when Amazon rain forest is deforested to grassland and cropland, the temperature increases by $3-5^{\circ} \mathrm{C}$. Other scientists continue to find deforestation in Amazon may induce a warmer climate and a decrease in precipitation because of lower evapotranspiration rates. The effect of vegetation on climate at the midlatitudes is highly uncertain [12].

The East Asian monsoon region, which is mainly located at the mid-latitudes, is an environmentally and ecologically fragile zone where climatic disasters, such as droughts, floods and extreme weather, happen frequently. The high population density in this area limits the sustainable use of land resources. So, vegetation degradation creates a very serious problem in this area. To cope with climate change, the Chinese government enacted a new plan called "China's Forestry Action Plan to Deal with Climate Change," which aims at continuing afforestation over two key regions. One is Three-North Shelterbelt Forest which is spread across northern China. The other is the Yangtze River, Zhujiang River (Pearl River) and Littoral Shelterbelt Forest. China plans to increase the current forest coverage from $18.2 \%$ to more than $26 \%$ by the year 2050 [13]. Numerous studies have analyzed the impact of afforestation in China on climate. Liu et al. [14] found afforestation increased precipitation, relative humidity, and soil moisture and reduced wind speed and air temperature across the Three-North Shelterbelt. Zhong et al. [15] and Song et al. [16] used a regional climate model to simulate the impact of afforestation over the Three-North Shelterbelt on local climate. However, many of these studies focused only on the Three-North Shelterbelt zone. So, it is essential to simulate the effect afforestation on climate in the regions of the Yangtze River, Zhujiang River and the Littoral Shelterbelt forests.

The East Asian monsoon region is a classical monsoon region where the land, atmosphere and ocean are strongly coupled. So, to analyze the impact of vegetation on climate, ocean variability should also be included. However, many studies only focus on land-atmospheric interactions, while ocean dynamics and variability are not included [17-19]. Dallmeyer and Clauseen [20] used a fully coupled climate model to simulate the influence of the East Asian monsoon region on present-day and mid-Holocene climate. They found ocean variability could modify the vegetation feedback signal. Ma et al. [21] found afforestation over the East Asian monsoon region would activate a wind-evaporationsea surface temperature (SST and WES) positive feedback over nearby ocean waters. This, in turn, induces increased water vapor transport inland; this water vapor then allows for greater precipitation and winter warming.

Many studies over the years have focused on the longterm effects of vegetation on climate. They discuss the feedback vegetation provides in a balanced ecosystem; however, few studies have focused on the short term effects of vegetation on climate, including a discussion of feedback from vegetation on climate after vegetation succession. Since the results of short-term simulations are strongly affected by the initial conditions, we adopted the ensemble integration model to enhance the signal-noise level of the simulation. Unlike previous studies, this study uses a fully coupled CCSM3.5 and ensemble simulation to analyze the vegetation feedback on the short-term climate and hydrological cycle. This study can provide a reference for government agencies charged with allocating land resources and making afforestation policies.

\section{Model and experimental design}

The model used in this study is the National Center for Atmospheric Research's Community Climate System Model Version 3.5 (CCSM3.5), which has four components including atmosphere (CAM), land (CLM), ice (CICE) and ocean (POP). All of these components exchange data through a coupler (CPL). The land component used in this study is the Community Land Model version 3.5 (CLM3.5-DGVM) including the Dynamic Global Vegetation Model (DGVM), which simulates the interaction of vegetation with atmosphere and land components. The horizontal resolution is $1.9^{\circ} \times 2.5^{\circ}$ and the land model includes ten soil layers. The horizontal resolution of the atmospheric component is the same as that of the land component. The atmospheric component has 26 layers with hybrid coordinates. The ocean and ice components use a POP grid, with a horizontal resolution of nearly $1^{\circ}$. The ocean component has 60 layers.

To analyze the short-term impacts of afforestation on climate over the East Asian monsoon region in the fully coupled model, a control run (CTL) with higher forest cover and a set of sensitive runs (TREE65) with lower forest cover were designed. In the control simulation (CTL), the global forest cover can range from 0 to $95 \%$ in each terrestrial grid cell. CTL is run for 80 years from the initial equilibrium state. We save every CTL's restart files at the end of each year, which includes the fractional cover of each plant function type. The sensitive modeling run (TREE65) is a set of ensemble experiments. At the start of each ensemble member, the fraction of the forest cover is reduced from $95 \%$ to $65 \%$ over the East Asian monsoon region (defined as $\left.19.89^{\circ}-41.0^{\circ} \mathrm{N}, 107.5^{\circ}-122.5^{\circ} \mathrm{E}\right)$. Each ensemble member runs for four years. The last three years are analyzed.

There are ten vegetation types in DGVM. Over the East Asian monsoon region, the major potential vegetation types are temperate evergreen forest, evergreen/deciduous mixed forest and grassland/steppe. The potential vegetation type in the model is close to the vegetation type in the real world. Notaro et al. [22] explored the vegetation feedback to climate in six global monsoon regions (including the East Asian monsoon region) by CCSM3.5-DGVM. In their study, the total vegetation coverage was reduced by $20 \%$ over the six global monsoon regions. Unlike their study, we focused 
on short-term effects of afforestation (increases in forest cover and decreases in grassland cover) on climate. Afforestation is defined here as forest cover replacing grassland cover. In real life, afforestation also includes the planting of trees in farmlands and in treeless barren mountain land. In this study, all differences are described as statistically significant at the $P<0.1$ level, based on the Student's $t$-test, unless stated otherwise.

\section{Results}

\subsection{Vegetation coverage and albedo change}

In response to modeled afforestation (CTL-TREE65), the area-average total forest and grassland cover change significantly across the East Asian monsoon region (Figure 1).
Figure 1 shows the average area of forestland coverage increases to $81 \%$ and the grassland coverage decreases to $8 \%$ (Table 1) in CTL. The total vegetation coverage is about $89 \%$. After modifying the upper limit of forest coverage to $65 \%$ across the East Asian monsoon region, the area of modeled average forest coverage decreases to $57 \%$ and the grassland coverage increases to $32 \%$ in TREE65. In the dynamic global vegetation model (DGVM), forested lands have an advantage over grasslands in being able to absorb solar radiation. With the same resource and radiation conditions, forests will replace grassland through ecological succession. Meanwhile, the total leaf area index (LAI) increases by 2.7 annually in CTL compared with TREE65 (Table 1). Also, the increased density of forested lands increases the roughness of the land surface across the East Asian monsoon region year round (Table 2).
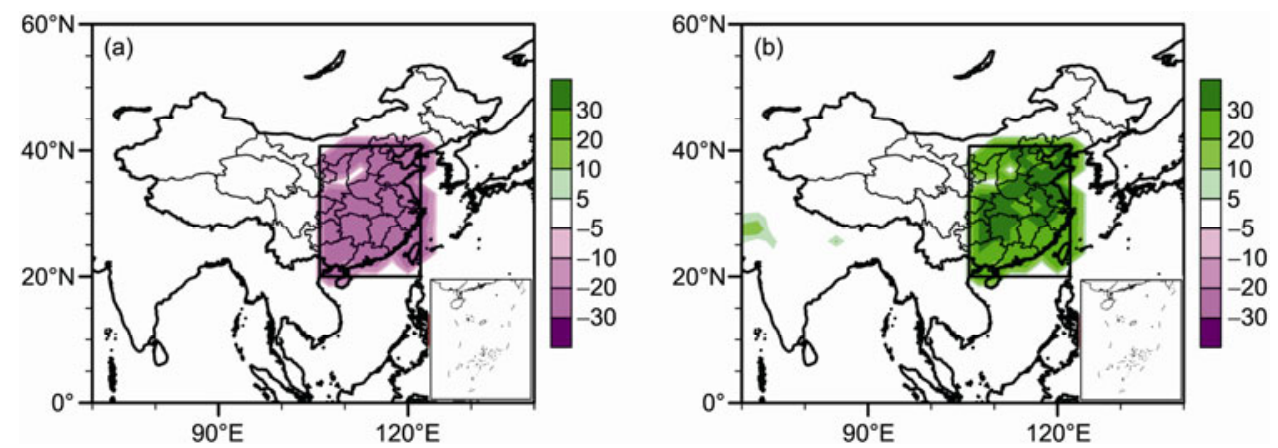

Figure 1 Differences in vegetation cover between the CTL and TREE65 simulations. (a) Total percent grassland cover; (b) total percent forest cover.

Table 1 Vegetation cover and albedo in different simulations across the East Asian monsoon region (CTL, TREE65)

\begin{tabular}{|c|c|c|c|c|c|}
\hline Simulation & Forest coverage $(\%)$ & Grassland coverage $(\%)$ & Total vegetation coverage (\%) & Leaf area index & Surface albedo \\
\hline CTL & 81 & 8 & 89 & 8.1 & 0.115 \\
\hline TREE65 & 57 & 32 & 90 & 5.4 & 0.137 \\
\hline CTL-TREE65 & 24 & -24 & -1 & 2.7 & -0.022 \\
\hline
\end{tabular}

Table 2 Differences between CTL and TREE65 simulations ${ }^{\mathrm{a})}$

\begin{tabular}{|c|c|c|c|c|c|}
\hline Variables & Spring & Summer & Autumn & Winter & Annual \\
\hline Ground temperature $\left({ }^{\circ} \mathrm{C}\right)$ & -1.12 & -1.46 & -0.77 & -0.37 & -0.93 \\
\hline Surface air temperature $\left({ }^{\circ} \mathrm{C}\right)$ & -0.13 & -0.38 & -0.27 & -0.10 & -0.22 \\
\hline Precipitation $\left(\mathrm{mm} \mathrm{d}^{-1}\right)$ & 0.12 & 0.17 & 0.01 & 0.08 & 0.09 \\
\hline Evapotranspiration $\left(\mathrm{mm} \mathrm{d}^{-1}\right)$ & 0.09 & 0.15 & 0.08 & 0.03 & 0.08 \\
\hline Total cloud cover $(\%)$ & 0.7 & 1.1 & 0.1 & 1.0 & 0.8 \\
\hline Surface stress $\left(\mathrm{kg} \mathrm{m}^{-1} \mathrm{~s}^{-2}\right)$ & 0.01 & 0.01 & 0.03 & 0.04 & 0.02 \\
\hline Downward longwave radiation $\left(\mathrm{W} \mathrm{m}^{-2}\right)$ & 0.9 & -0.4 & -0.3 & 1.1 & 0.3 \\
\hline Upward longwave radiation $\left(\mathrm{W} \mathrm{m}^{-2}\right)$ & -1.3 & -3.1 & -1.8 & -0.5 & -1.7 \\
\hline Surface net shortwave radiation $\left(\mathrm{W} \mathrm{m}^{-2}\right)$ & 0.8 & -0.4 & 1.9 & 1.6 & 1.0 \\
\hline Downward shortwave radiation $\left(\mathrm{W} \mathrm{m}^{-2}\right)$ & -3.7 & -4.9 & -1.6 & -2.2 & -3.1 \\
\hline Upward shortwave radiation $\left(\mathrm{W} \mathrm{m}^{-2}\right)$ & -4.5 & -4.5 & -3.5 & -3.8 & -4.1 \\
\hline Total sensible heat flux $\left(\mathrm{W} \mathrm{m}^{-2}\right)$ & 0.9 & -1.8 & 0.3 & 2.3 & 0.4 \\
\hline Sensible heat flux from ground $\left(\mathrm{W} \mathrm{m}^{-2}\right)$ & -3.1 & -2.2 & -2.4 & -3.0 & -2.7 \\
\hline Sensible heat flux from vegetation $\left(\mathrm{W} \mathrm{m}^{-2}\right)$ & 4.0 & 0.4 & 2.8 & 5.3 & 3.1 \\
\hline Latent heat from canopy evaporation $\left(\mathrm{W} \mathrm{m}^{-2}\right)$ & -6.1 & $-\mathbf{1 0 . 0}$ & -5.3 & -2.1 & -5.9 \\
\hline Latent heat from canopy evaporation $\left(\mathrm{W} \mathrm{m}^{-2}\right)$ & 2.8 & 4.4 & 2.0 & 1.2 & 2.6 \\
\hline Latent heat from transpiration $\left(\mathrm{W} \mathrm{m}^{-2}\right)$ & 6.0 & 10.1 & 5.8 & 1.7 & 5.9 \\
\hline Heat flux into ground $\left(\mathrm{W} \mathrm{m}^{-2}\right)$ & -0.7 & $-\mathbf{0 . 3}$ & 0.6 & 0.1 & $-\mathbf{0 . 1}$ \\
\hline
\end{tabular}

a) Bold indicates a statistically significant difference at $P<0.1$. 
Vegetation cover and type are import factors influencing the surface albedo. The surface albedo over the East Asian monsoon region is 0.137 in TREE65. Since surface albedo of grassland is greater than that of forested land, afforestation across the East Asian monsoon region leads a $16 \%$ decrease in the surface albedo. The simulation shows the surface albedo decreases to 0.115 in the CTL simulation.

\subsection{Response of temperature and surface energy balance}

Changes in vegetation type can affect the surface energy budget, ground temperatures and surface air temperatures by modifying the surface albedo. In response to modeled afforestation, ground temperatures decreases by $0.93^{\circ} \mathrm{C}$ annually (Table 2). Ground temperatures decrease by $1.12^{\circ} \mathrm{C}$, $1.46^{\circ} \mathrm{C}, 0.77^{\circ} \mathrm{C}$ and $0.37^{\circ} \mathrm{C}$ in spring, summer, autumn and winter, respectively (Table 2). Meanwhile, surface air temperature also decreases annually and seasonally (Figure 2(a)-(e)). The maximum reduction occurs in summer, and the minimum reduction occurs in winter (Table 2). Surface air temperature decreases by $-0.13^{\circ} \mathrm{C}$ and $-0.27^{\circ} \mathrm{C}$ during spring and autumn, respectively (Table 2 ).

The response to components in the surface energy budget to increased LAI are analyzed, including latent heat flux, sensible heat flux, longwave radiation, and shortwave radiation (Figure 3). Afforestation can affect ground and surface air temperatures by redistributing energy. We examine the components of surface energy budget over the East Asian monsoon region. Note the total shortwave radiation is the difference between solar radiation and reflective shortwave radiation, and toward/away from the surface are defined as positive/negative, respectively. In response to the increase in LAI, total shortwave radiation significantly increases in all
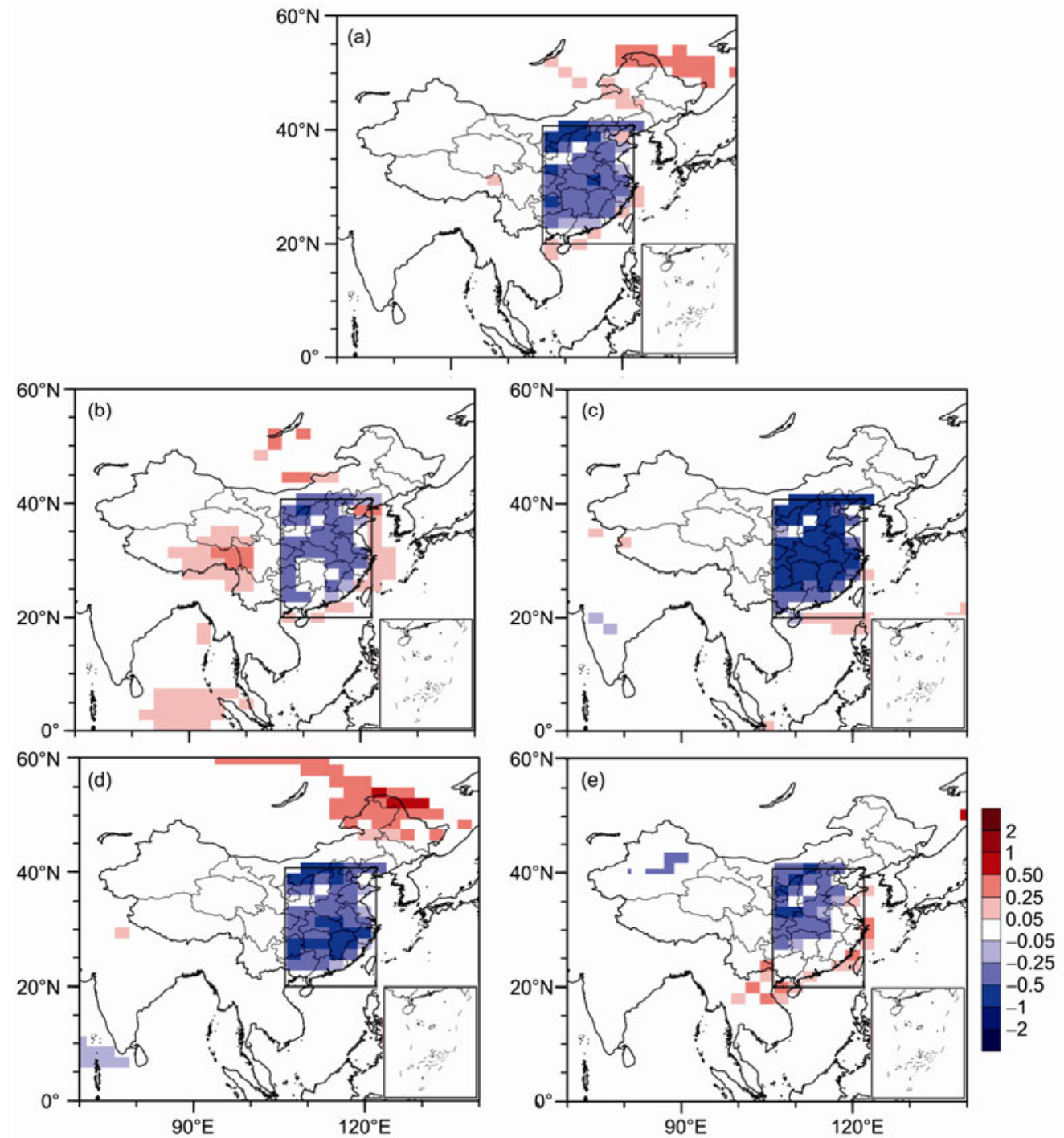

Figure 2 Differences in surface air temperature $\left({ }^{\circ} \mathrm{C}\right.$ ) between the CTL and TREE65 simulations. (a) Annual mean; (b) spring; (c) summer; (d) autumn; (e) winter. Shading indicates statistically significant difference at $P<0.1$. 

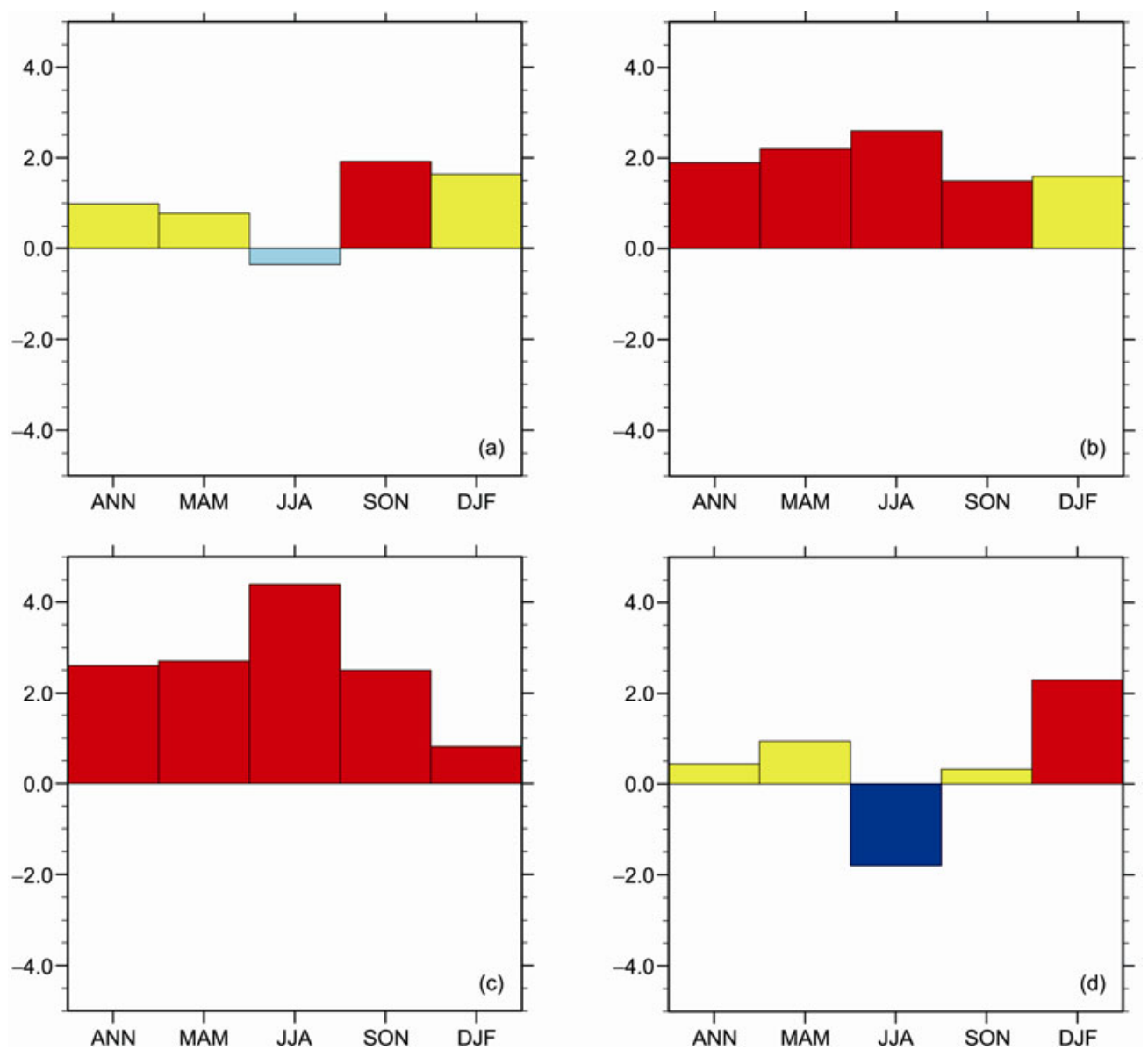

Figure 3 Differences in energy budget components between the CTL and TREE65 simulations. (a) Net shortwave radiation; (b) net longwave radiation; (c) latent heat flux; (d) sensible heat flux. Red and blue indicate statistically significant differences at $P<0.1\left(\mathrm{Unnit}^{\mathrm{W}} \mathrm{W} \mathrm{m}^{-2}\right)$.

of the seasons except in summer. Especially during autumn, the total modeled shortwave radiation increases significantly by $1.9 \mathrm{~W} \mathrm{~m}^{-2}(1.4 \%)$ and also increases by $1.0 \mathrm{~W} \mathrm{~m}^{-2}(0.6 \%)$ annually (Figure 3(a), Table 2). This is mainly attributable to the increase in albedo related to the increase in LAI (Table 2). However, during summer, the increase in total cloud cover blocks part of the downward shortwave radiation, which offsets the increase in reflective radiation caused by the increase in albedo.

Total longwave radiation is the difference between downward longwave radiation and reflective longwave radiation. As is done with the total shortwave radiation described above, toward surface is defined as positive. In response to afforestation, total modeled longwave radiation increases significantly by $1.9 \mathrm{~W} \mathrm{~m}^{-2}$ (3.9\% (Figure 3(b), Table 2)), annually and it also increases in spring, summer and autumn. The most robust change of total longwave radiation is the increase in summer $\left(2.6 \mathrm{~W} \mathrm{~m}^{-2}\right.$ (Figure $3(\mathrm{~b})$, Table 2)).

In response to afforestation over the East Asian monsoon region, the total latent flux significantly increases year-round because of the increase in LAI. The total latent heat flux includes three items: ground evaporation, canopy evapora- tion and transpiration. Annual total latent heat flux increases $2.6 \mathrm{~W} \mathrm{~m}^{-2}(3.4 \%)$ with afforestation. The total latent heat flux increases during spring $\left(2.7 \mathrm{~W} \mathrm{~m}^{-2}, 3.6 \%\right)$, summer $\left(4.4 \mathrm{~W} \mathrm{~m}^{-2}, 3.6 \%\right)$, autumn $\left(2.5 \mathrm{~W} \mathrm{~m}^{-2}, 3.5 \%\right)$ and winter $\left(0.8 \mathrm{~W} \mathrm{~m}^{-2}, 2.6 \%\right.$ (Figure 3(c), Table 2)). The largest and smallest latent heat response to afforestation occurs in the summer growing season and in winter, respectively. Sensible heat flux comprises two parts from ground and vegetation. Annual total sensible heat flux increases slightly on average; however, it significantly declines in summer by 1.8 $\mathrm{W} \mathrm{m} \mathrm{m}^{-2}(7.3 \%)$ and increases in winter by $2.3 \mathrm{~W} \mathrm{~m}^{-2}(8.3 \%$ (Figure 3(a), Table 2)).

Vegetation cover change can influence not only on local climate, but also influences remote regional climate. Afforestation over the East Asian monsoon region induces a warm climate over surrounding area. SSTs increase over the South and East Asian seas during winter and following spring (Figure 2(b),(e)). Also, the surface air temperature increases over Northeast China and along the border with Russia during autumn mainly because the increase in LAI induces more evapotranspiration over the East Asian monsoon region. In turn, the increased water vapor transport to Northeast China allows the formation of additional clouds 
which trap more longwave radiation thus heating ground and surface air.

In considering the above results, one can see, in response to the increasing LAI, the annual total longwave radiation flux and latent heat flux changes is robust. The increase in total latent heat flux is greater than the increase in the total longwave radiation. An increase of total shortwave radiation flux and total longwave radiation can warm the earth's surface. An increase in latent heat flux can induce cooling. Over the East Asian region, in response to afforestation, the increase in evapotranspiration leads to summer cooling. During winter, the increased forest cover produces higher roughness; this increases energy exchange, leading to higher sensible heat flux and latent heat flux. Both of the increases in heat flux can lead to surface warming.

\subsection{Response of atmospheric circulation and precipitation}

Afforestation can influence the precipitation and hydrological cycles by modifying the atmosphere circulation. Anomalies of ascent occur during most of the year, such as in January-February, May, and July-December across the East Asian monsoon region (Figure 4(a)). The most robust anomalous ascent occurs in April at 700-850 hPa (Figure 4(a)). Along with this ascent anomaly, specific humidity increases significantly during April and May (Figure 4(b)). This increase in moisture and ascent flow produced additional precipitation in April (7\%). This is consistent with the increase in available precipitable water which increases in April (3\%) and May (2\%).

Modest modeled increases in precipitation occur over the East Asian monsoon region during spring $\left(0.12 \mathrm{~mm} \mathrm{~d}^{-1}\right.$ (Figure 5, Table 2)) and winter $\left(0.08 \mathrm{~mm} \mathrm{~d}^{-1}\right.$ (Figure 5, Table 2)). The largest change in precipitation occurs in summer $(0.17$

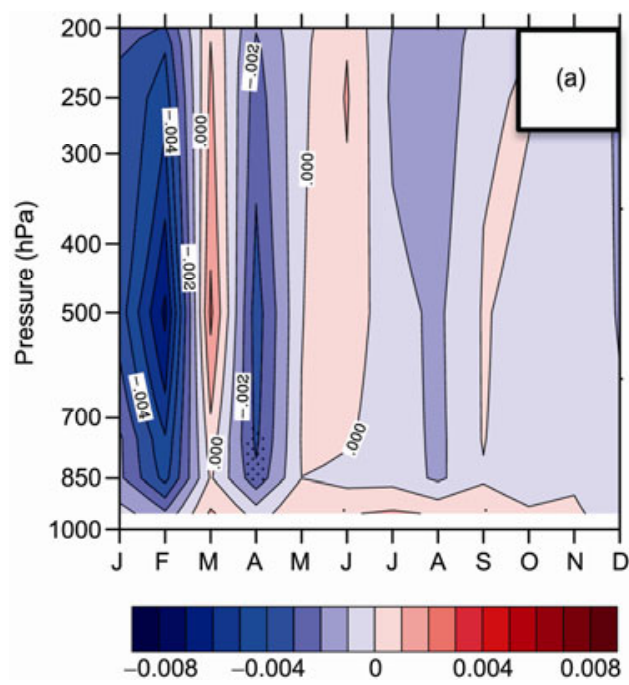

$\mathrm{mm} \mathrm{d}^{-1}$ (Figure 5, Table 2)). The small change in autumn precipitation $\left(0.01 \mathrm{~mm} \mathrm{~d}^{-1}\right.$ (Figure 5 , Table 2$)$ ) is not statistically significant. Because forest cover increases, ET increases in spring, summer, autumn, and winter by $0.09,0.15$, 0.08 , and $0.03 \mathrm{~mm} \mathrm{~d}^{-1}$, respectively. During spring and summer, the increase in precipitation exceeds the increase in ET, as indicated by the change of PME (precipitation minus evapotranspiration) $>0$, suggesting an external source of moisture to the region. Here we mainly focus on the area-averaged responses to afforestation but note that over the East Asian monsoon region, the rain belt moves with the seasons. The response of precipitation to increased forest cover also differs according to latitudes and seasons. Increased forest cover induces a wetter climate in southern China and a slightly drier climate in north China. Overall, afforestation in the East Asian monsoon region leads to a wetter climate.

With increased forest cover, both local precipitation and ET increase, suggesting the local hydrology cycle is amplified. The response of ET to increased forest cover also differs with the seasons. The response of ET to increased forest cover is robust during spring and summer, but is not statistically significant during winter.

\subsection{Response of soil water and surface wind}

Afforestation influences surface wind speed by creating an increase in surface roughness resulting in reduced surface wind speeds (Figure 6). Also, this induces convergence and anomaly ascent in the atmosphere. The change in annual surface wind speed is robust over most parts of the East Asian monsoon region, except in Henan, Jiangsu and Zhejiang provinces (Figure 6(a)). During summer to winter surface wind speed significantly decreases in response to afforestation over the East Asian monsoon region (Figure 6(c)-(e)). In spring, the most robust decrease of surface wind speed is

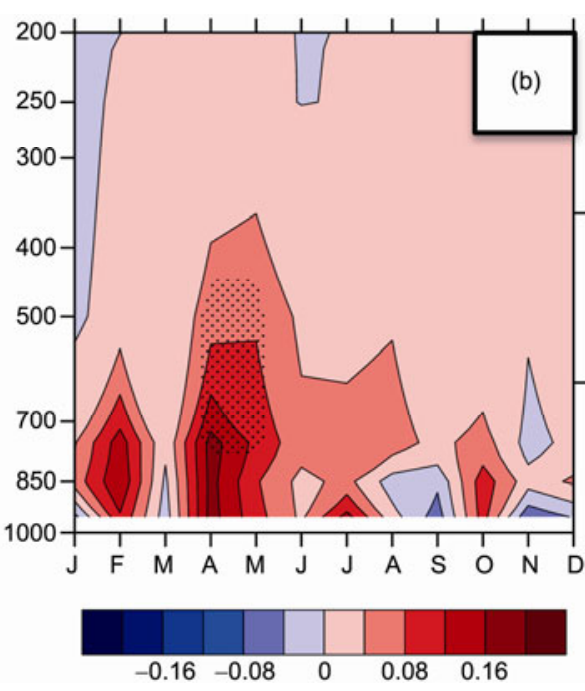

Figure 4 Differences between the CTL and TREE65 simulations. (a) Vertical motion (omega, Unit: Pa s ${ }^{-1}$ ); (b) specific humidity (Unit: kg kg ${ }^{-1}$ ). Black dots indicate statistically significant difference at $P<0.1$. 


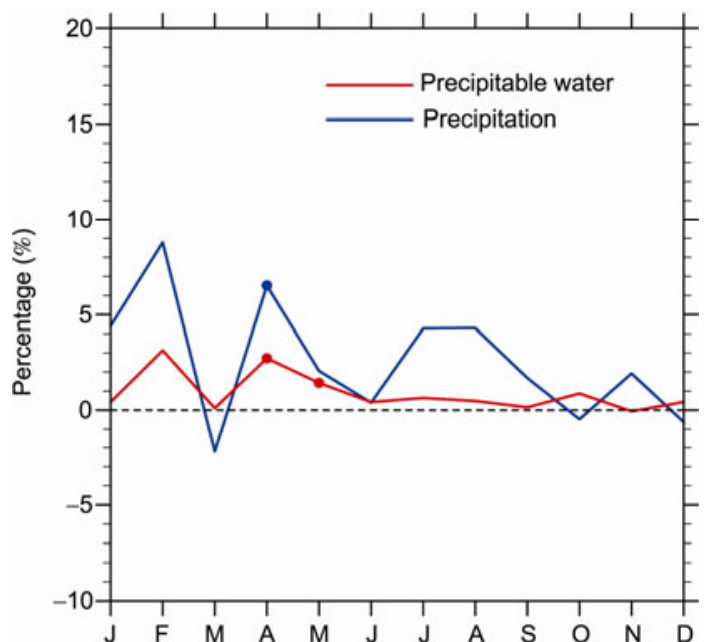

Figure 5 Differences in precipitation percentage (blue line) and precipitable water percentage (red line). Colored dots indicate statistically significant difference at $P<0.1$. seen over the southern part of the East Asian monsoon region (Figure 6(b)), but the change is not significant over the northern part of the region. Aside from the changes over the East Asian monsoon region, surface wind speeds also significantly decreases over the South and East Asian seas, particularly during winter.

In response to afforestation, soil water changes by both depth and season because tree roots penetrate deeper than grass roots. In winter, soil water decreases significantly (0$100 \mathrm{~cm}$ ) with soil water decreasing with increased depth (Figure 7). The increased precipitation induces greater amounts of soil water (Figure 7). The increased precipitation from April to August results in an increase in soil water near the surface $(0-40 \mathrm{~cm})$. Soil water also increases in deeper layers $(40-100 \mathrm{~cm})$ in August and September. With the increase in precipitation in spring, summer and autumn $(0.12,0.17$, and $0.01 \mathrm{~mm} \mathrm{~d}^{-1}$, respectively), the shallow soil water increases (Table 2). ET increases by $0.08 \mathrm{~mm} \mathrm{~d}^{-1}$, which is greater than
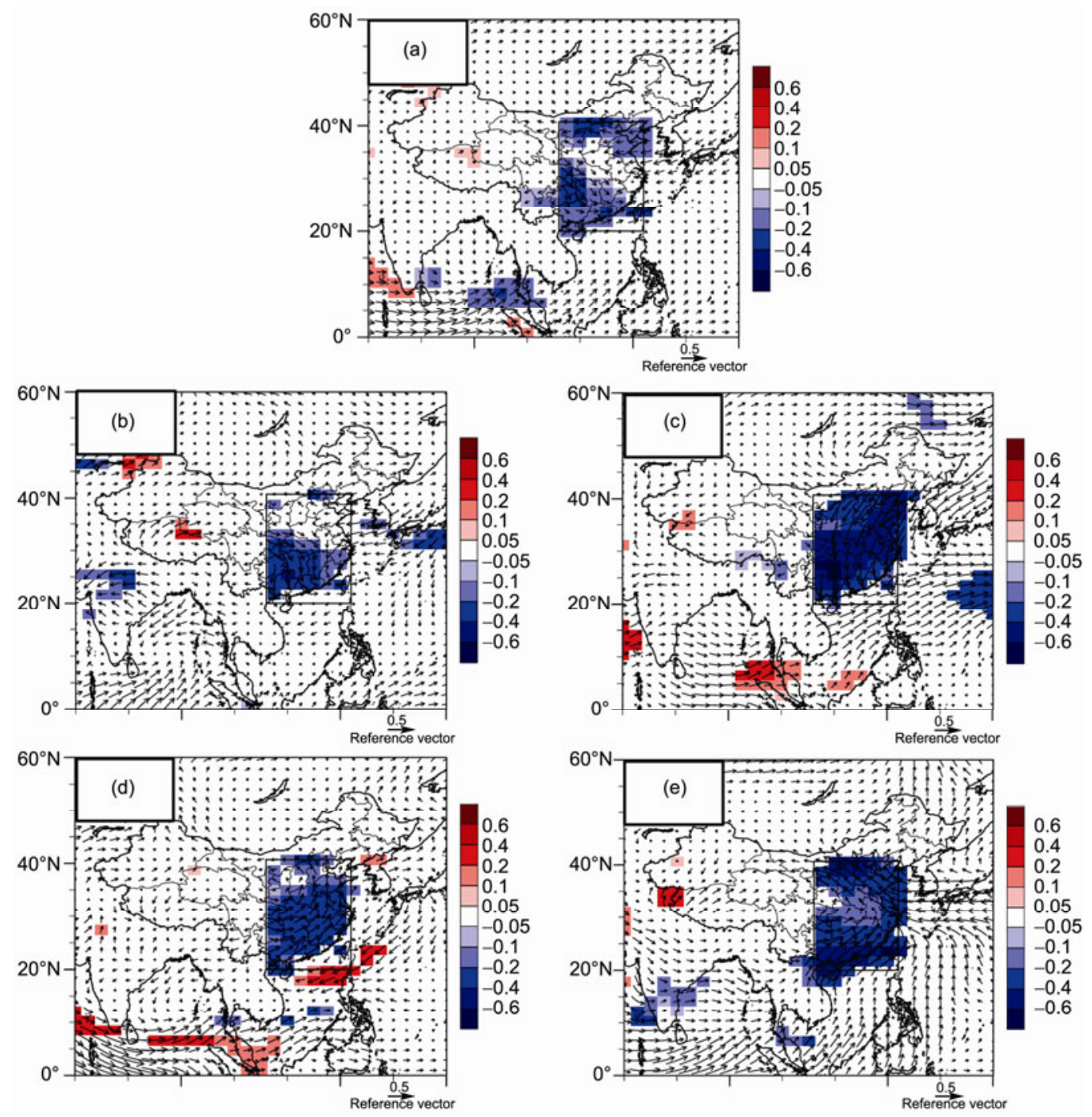

Figure 6 Differences in wind speed (color shading) and wind vector between the CTL and TREE65 simulations (Unit: $\mathrm{m} \mathrm{s}{ }^{-1}$ ). (a) annual mean; (b) spring; (c) summer; (d) autumn; (e) winter. Shading indicates statistically significant difference at $P<0.1$. 


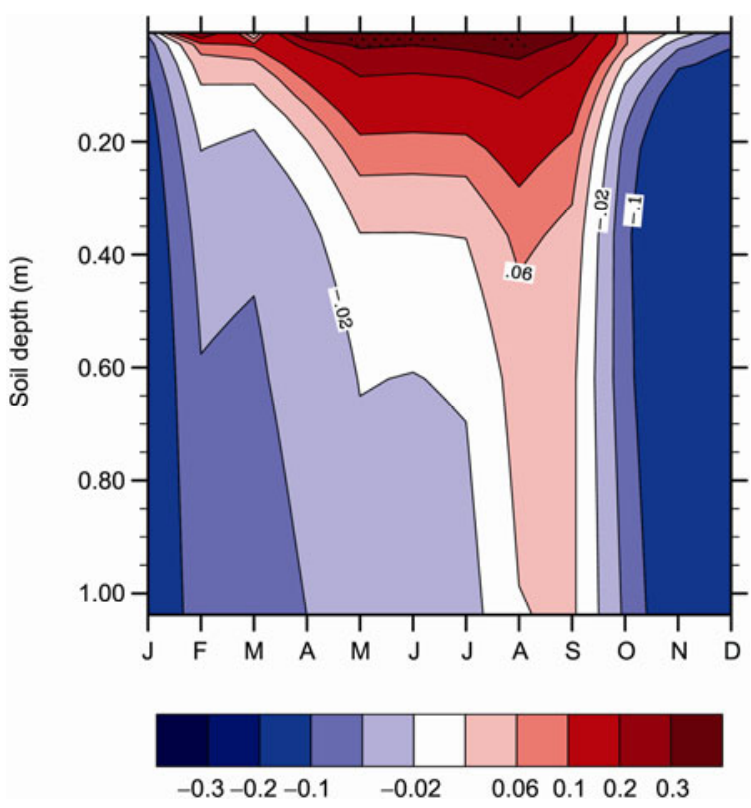

Figure 7 Differences between the CTL and TREE65 simulations: volumetric soil water (Unit: \%).

precipitation in autumn, so the soil water decreases gradually (Figure 7).

\section{Discussion and conclusions}

To analyze the impact of afforestation across the East Asian monsoon region, a control simulation and ensemble experiment were run with CCSM3.5 producing the following findings:

(1) With increases in forest cover over the East Asian monsoon region, the increasing in LAI will induce a smaller surface albedo. Also, afforestation will affect surface air and ground temperatures by redistributing surface energy. Surface air temperatures decrease during spring $\left(-0.93^{\circ} \mathrm{C}\right)$ and during winter $\left(-0.40^{\circ} \mathrm{C}\right)$ with the most robust temperature change occurring during summer $\left(-1.46^{\circ} \mathrm{C}\right)$. The increase in ET is the main driving force behind summer cooling. The increases in latent and sensible heat fluxes are the main reason for winter cooling. The increase of forest cover influences not only local climate but also nearby areas. The initial surface wind speed decreases over the East and South China seas because surface roughness increases in the modeled afforestation in East Asian. Also, the decrease in surface wind speed induces less evaporation and warmer SSTs over East and South China Sea.

(2) The increase in forest cover can influence atmospheric circulation and affect local precipitation. First, the increased forest cover results in a greater LAI, which leads to increases in ET and precipitable water. Second, the increased forest cover induces greater surface roughness leading to airflow convergence and anomalous ascent of air masses. Both of these effects lead to increased precipitation over the East Asian monsoon region. In April and May, anomalous ascent and more available water vapor induce increased precipitation over the East Asian monsoon region. Also, the hydrological cycle is amplified by afforestation. The responses of precipitation and ET to afforestation are greater in the summer growing season than that in winter. Moreover, the increase in precipitation leads to increased soil water in spring, summer and autumn.

Based on the above findings, an increase in forest cover significantly influences the local energy budget and shortterm climate. Afforestation decreases surface air temperatures and increases local precipitation. This demonstrates afforestation is a powerful method to mitigating climate change. Unlike previous studies, we focus on the effects of vegetation feedback on short-term climate. Ma et al. [21] found an increase in LAI leads to long-term winter warming because of the involvement of the WES positive feedback mechanism. The reduction of initial wind speed results in positive WES feedback and warms SSTs over East and South China seas as a result. In turn, the anomalous warming accumulates, influences atmospheric circulation and leads to winter warming of the East Asian monsoon region. This indicates vegetation feedback is dependent on the time scale. Note the CCSM3.5-DGVM vegetation type classifications do not include agriculture, which has a slightly different impact on climate than grassland. This is the limitation of this study.

The authors would like to thank the two anonymous reviewers for their valuable suggestions and comments. This work was supported by the Major Research Program for Global Change Study (2010CB950503 and 2012CB955201) and the National Basic Research Program of China (2009CB421402 and 2013CB956004).

1 Fu C B, Yuan H L. An virtual numerical experiment to understand the impacts of recovering natural vegetation on the summer climate and environmental conditions in East Asia. Chin Sci Bull, 2001, 46: 1199-1203

2 Zheng Y Q, Qian Y F, Miao M Q, et al. The effects of vegetation change on regional climate I: Simulation results (in Chinese). Acta Meteorol Sin, 2002, 60: 17-29

3 Zhang J Y, Dong W J, Fu C B. Impact of land surface degradation in northern China and southern Mongolia on regional climate. Chin Sci Bull, 2005, 50: 75-81

4 Liu F, Chao J P. Semi-analytical analysis of the response of the air temperature over the land surface to the global vegetation distribution. Chin Sci Bull, 2009, 54: 2499-2505

5 Wu L Y, Zhang J Y, Dong W J. Vegetation effects on mean daily maximum and minimum surface air temperatures over China. Chin Sci Bull, 2011, 56: 900-905

6 Di Y B, Wang H M, Ma Z Q, et al. Carbon storage and its allocation pattern of forest ecosystems with different restoration methods in subtropical China (in Chinese). Chin Sci Bull (Chin Ver), 2012, 57: 1553-1561

7 Charney J G. Dynamics of deserts and drought in the Sahel. Quart J Roy Meteor Soc, 1975, 101: 193-202

8 Notaro M, Liu Z Y. Joint statistical and dynamical assessment of simulated vegetation feedbacks on climate over the boreal forests. Climate Dyn, 2008, 31: 691-712

9 Chen G, Notaro M, Liu Z Y, et al. Simulated local and remote bio- 
physical effects of afforestation over Southeast United States in boreal summer. J Clim, 2012, 25: 4511-4522

10 Thomas G, Rowntree P R. The boreal forests and climate. Quart J Roy Meteor Soc, 1992, 118: 469-497

11 Dickinson R E, Kennedy P. Impacts on regional climate of Amazon deforestation. Geophys Res Lett, 1992, 19: 1947-1950

12 Bonan G B. Forests and climate change: Forcings, feedbacks, and the climate benefits of forests. Science, 2008, 320: 1444-1449

13 Yang X H, Wang X P, Li N Y. Combating climate change: What will China's industry do? AMBIO, 2010, 39: 340-343

14 Liu Y Q, Stanturf J, Lu H Q. Modeling the potential of the northern China forest shelterbelt in improving hydroclimate conditions. JAWRA, 2008, 44: 1176-1192

15 Zhong Z, Wang H J, Xiong W Y, et al. Numerical study of environmental effects of the tree north shelterbelts system part (I): Model description and verification (in Chinese). J PLA Univ Sci Tech, 2001, 2: 7-12

16 Song S, Ju Y M, Wang H J. Possible impacts of land use change on regional rainfall associated with orderly human activities (in Chinese).
Clim Environ Res, 2008, 13: 759-774

17 Lü S H, Chen Y C. The influence of northwest China afforestation on regional climate in China (in Chinese). Plateau Meteorol, 1999, 18: 416-424

18 You H L, Zhu H Y, Xiong S Q, et al. Climatic change due to changing vegetation area in China as simulated by a regional climate model (in Chinese). J Chengdu Univ Inf Tech, 2010, 25: 301-307

19 Chen J M, Zhao P, Guo X Y. Numerical simulation of the impact of changes in the vegetation in the western China on the summer climate over the northern China (in Chinese). Acta Meteorol Sin, 2010, 68: 251-259

20 Dallmeyer A, Clauseen M. The influence of land cover change in the Asian monsoon region on present-day and mid-Holocene climate. Biogeosciences, 2011, 8: 1499-1519

21 Ma D, Notaro M, Liu Z Y, et al. Simulated impacts of afforestation in East China Monsoon region as modulated by ocean variability. Clim Dyn, 2012, doi: 10.1007/s00382-012-1592-9

22 Notaro M, Chen G S, Liu Z Y. Vegetation feedbacks to climate in the global monsoon regions. J Clim, 2011, 24: 5740-5756

Open Access This article is distributed under the terms of the Creative Commons Attribution License which permits any use, distribution, and reproduction in any medium, provided the original author(s) and source are credited. 